\title{
Difficulties of 6th Grade Elementary School Students in Solving the Four Basic Fundamental Operations: Addition, Subtraction, Multiplication and Division of Natural Numbers
}

\author{
Celia Finck Brandt1', Tânia Stella Bassoi'², Ana Lúcia Pereira Baccon³ \\ ${ }^{1}$ Department of Methods and Teaching Techniques, State University of Ponta Grossa (UEPG), Parana, Brazil \\ ${ }^{2}$ Department of Mathematics, State University of Western Paraná, Cascavel, Brazil \\ ${ }^{3}$ Department of Mathematics and Statistics, State University of Ponta Grossa (UEPG), Parana, Brazil \\ Email: brandt@bighost.com.br, tstellabassoi@gmail.com, ana.baccon@hotmail.com
}

Received 29 June 2016; accepted 15 August 2016; published 18 August 2016

Copyright (C) 2016 by authors and Scientific Research Publishing Inc.

This work is licensed under the Creative Commons Attribution International License (CC BY).

http://creativecommons.org/licenses/by/4.0/

(c) (i) Open Access

\begin{abstract}
The results of this study point out the contributions of the theory of Conceptual Fields to identify the nature of the mistakes made by students of the 6th year of elementary school in solving mathematical questions with ten natural numbers. We ask: What are the concepts and theorems put into action to carry out the operations of addition, subtraction, multiplication and division with natural numbers? The concepts and theorems in action related to the understanding of the decimal numbering system structure are responsible for the errors? The mistakes are due to the understanding of the organization of representation registers (word and Arabic notation)? As a result, we find that students have the addition of errors and subtraction errors by misunderstanding of the structure of the Numbering Decimal Positional System, errors due to lack of meaning assignment to the operations of addition, subtraction, multiplication and division, and also the numbers of Arabic script which induce errors in the handling of algorithms.
\end{abstract}

\section{Keywords}

Mathematical Operations, Concepts and Theorems in Action, Conceptual Fields of Mathematical Operations, Natural Numbers 


\section{Introduction}

This text presents the results of a research on the performance of addition, subtraction, multiplication and division with natural numbers of students from 6th grade of elementary school. The answers to questions posed characterized the empirical data, submitted to analysis in the light of the theory of Conceptual Fields of Gérard Vergnaud (1990) to answer the following questions: What are the concepts and theorems put into action to carry out the operations of addition, subtraction, multiplication and division with natural numbers, students from 6th grade of elementary school? The concepts and theorems in action related to the decimal number system structure are responsible for the errors? The errors are due to the understanding of the algorithm structure? The errors are due to the understanding of the organization of representation registers (word and arabic notation)?

With the development of the survey intended to achieve the following objectives: to explain the concepts and theorems put into action to carry out the operations of addition, subtraction, multiplication and division with natural numbers, by students of the 6th grade of primary education; explicit the students' understanding of the SND, at the time of use of operative algorithms; unveil the chances that students manifest to justify strategies and procedures used to perform addition, subtraction, multiplication and division with natural numbers; point the conceptual field (set of situations and set of concepts) necessary to perform addition, subtraction, multiplication and division operations with natural numbers.

\section{Literature Review}

Different research or experiments were conducted to discuss and analyze the students' difficulties to perform addition, subtraction, multiplication and division with natural numbers. Some of these researches or experiences with errors in these operations, others have experience reports that can help to overcome the difficulties. Some of these stories and experiences will be shown below in order to verify contributions to overcome the student's difficulties.

In this direction arises the article by Felicio and Policarpo (2015) entitled "The use of games as a teaching resource" which presents the story of an experiment that uses mathematical games as a teaching resource in the teaching learning process carried out with students from sixth grade of elementary education. These games were used as target for students solve the four basic operations, addition, multiplication, division and subtraction with natural numbers. The authors state that the use of games as a teaching and learning strategy in the classroom is a pedagogical resource that allows students to develop operations solving methods with natural numbers, stimulating their creativity and participation, because to win the student has to make use of strategies that allow them to hone the skills that make up the logical reasoning.

The student's difficulties to perform operations was the reason that inspired Pedro D'Alcantara Almeida Lisboa to propose a method for performing operations with natural numbers. This method was called "reasoned Arithmética" and was presented by Elenice de Souza Ledron Zuin in her article called "The four fundamental operations in the 'reasoned Arithmética'” by Peter D'Alcantara Lisboa, published in 1983. According to the author, Lisboa, in his book, seeks to encourage students' thinking showing an analytical method that accompanies the practical methods (algorithms) to perform addition, subtraction, multiplication and division with natural numbers. This method consists in the decomposition of numbers allowing visualization of the various steps used in the use of algorithms procedures that are not understood but carried out mechanically. The underlying process in the execution of the algorithm becomes explicit from the decomposition of numbers. Lisboa, according to Zuin (2005) sought to focus on the reasoning and exposed processes.

This was done because the difficulties were greater for operations with reservation and for multiplication and division or operations with numbers with zeros interspersed or in the end (e.g. 1000 - 132).

Some examples illustrate the method used by Lisboa according to Zuin (2005). is See a example method for subtraction with natural numbers in "Figure 1".

See "Figure 2" for an example for multiplication with natural numbers used by Lisboa according to Zuin (2005).

See "Figure 3" for an example for addition with natural numbers used by Lisboa according to Zuin (2005).

According to Zuin (2005) the analytical method presented by Lisboa first purposed understanding the meaning of operations by the students after the proposed work with the algorithms synthetically.

The article entitled "Learning Difficulties arithmetic in the early grades" written by Bertini and Passos (2016) turned to the presented difficulties by the students of third grade of school. Also for the origin of these difficulties 


\begin{tabular}{|c|c|c|c|c|c|c|}
\hline 1500 & $=1000+$ & 500 & + & 0 & + & $\mathbf{0}$ \\
\hline$\underline{-1498}$ & $=-(1000+$ & 400 & + & o & + & 0) \\
\hline $\begin{array}{l}\text { Oo autor desta } \\
\text { atender a neces } \\
\text { unidades de } 0 \mathrm{u}\end{array}$ & $\begin{array}{l}\text { Ica que par: } \\
\text { ssidade da } \mathrm{s} \\
\text { Inidades, à } \mathrm{p}\end{array}$ & $\begin{array}{l}\text { ealiz: } \\
\text { ção, } \\
\text { pio. }\end{array}$ & esta & $\begin{array}{l}\text { raçã } \\
\text { e é n }\end{array}$ & oder & $\begin{array}{l}\text { escrever } 500=400+90+10 \text {, para } \\
\text { ubtrair } 90 \text { dezenas de } 0 \text { dezenas e } 8\end{array}$ \\
\hline & & 400 & & 90 & & 10 \\
\hline 1500 & $=1000+$ & 500 & + & o & + & $\mathbf{0}$ \\
\hline-1498 & $=-(1000+$ & 400 & + & 90 & + & 8) \\
\hline & 0 & 0 & & 0 & & 2 \\
\hline
\end{tabular}

Source: Zuin (2005).

Figure 1. Lisboa method for subtraction with natural numbers.

\begin{tabular}{|c|c|c|c|c|c|c|c|c|}
\hline 33 & $=$ & & & & & 30 & + & 3 \\
\hline$\times 14$ & $=$ & & & & & 10 & + & 4 \\
\hline 132 & $=$ & 100 & + & 20 & + & 10 & + & 2 \\
\hline 33 & $=$ & $\underline{300}$ & + & 30 & & & & \\
\hline & & 400 & + & 50 & + & 10 & + & $2=462$ \\
\hline
\end{tabular}

Source: Zuin (2005).

Figure 2. Lisboa method for multiplication with natural numbers.

\begin{tabular}{|c|c|c|c|c|c|c|c|c|}
\hline 4000 & $=$ & 4000 & & & & & & \\
\hline 395 & $=$ & 0 & + & 300 & + & 90 & + & 5 \\
\hline 1453 & $=$ & 1000 & + & 400 & + & 50 & + & 3 \\
\hline \multirow[t]{3}{*}{$\underline{1789}$} & $=$ & $\underline{1000}$ & + & 700 & + & 80 & + & 9 \\
\hline & & 6000 & + & $1000+400$ & $\underbrace{+}$ & $200+20$ & + & $10+7$ \\
\hline & & & 7000 & + & 600 & + & 30 & +7 \\
\hline
\end{tabular}

Source: Zuin (2005).

Figure 3. Lisboa method for addition with natural numbers.

and the possible forms of intervention to minimize them. The authors have developed a practical study, which investigated the main mistakes made by 64 students ranging in age from 9 to 13 years old. A worksheet containing twenty-four accounts - twelve additions and twelve subtractions—involving different levels of difficulty, was proposed to students so that the errors could be observed in the mechanical operations. The authors presented the different levels of difficulty for the analysis were as comprehensive as possible. The authors observed that the addition and subtraction of small numbers (only involving unit and dozen) and had no need for amalgamations, there were practically no errors. By analyzing the mistakes, it was possible to establish some categories according to the type of shown error.

The error categories were: wrong reproduction of the proposal (the student plays the number or the operation displayed incorrectly); error count (the student misses to make the count of one of the columns especially when the digits of the number are greater than five or in the case of subtraction when, due to the exchange, the number of which must subtract is greater than ten); error in the spatial organization (the student does not set correctly the unit columns, dozen); error when adding or subtracting zero (the zero appears as an impediment in the realization of the algorithm both addition and subtraction and some students believe that the addition or subtraction of any number with zero results in zero itself); error when using regroupings (this is the kind of error that occurs more frequently especially in subtraction and in most cases have their origin in the lack of understanding the decimal system); inverted operation (this error is specific to the subtraction when the minuend has lower numbers than the subtrahend, the student performs "subtrahend less minuend"); error compensation (the use of this algorithm students are wrong to "borrow" and "return").

It is noteworthy that some identified errors in the survey and presented in the article are of the same nature of the errors found in our research. The difference is that in the authors' research the errors are identified and not 
analyzed as we do in our research.

The study by Adriano Romero de Oliveira Lira entitled "A study about division of natural numbers with 5th grade students of elementary school” provides used procedures by students in division operations with natural numbers. These procedures were categorized in: mental calculation, use the subtraction and not use the subtraction as in "Figure 4".

Next, for each proposed division, the answers were inserted into a table showing the percentage of each type of response that were inserted in the following categories R1 $\rightarrow$ You made certain categories and gave right answer; R2 $\rightarrow$ he made right and gave the wrong answer; R3 $\rightarrow$ wrong've made and gave right answer; R4 $\rightarrow$ he made wrong and gave wrong answer; R5 $\rightarrow$ not made and gave right answer; R6 $\rightarrow$ not made and gave wrong answer; R7 $\rightarrow$ not made and no answer.

The proposed divisions were: $280 \div 8$; $183 \div 9$; $960 \div 15 ; 1001 \div 25$; $9234 \div 513$.

The author also proposed five problems whose resolution could require the division. For these problems new categories were created to insert the students' responses: T1-answered right using strategy; T2-answered wrong using strategy; T3 answered right without using strategy; T4 answered wrong without using strategy; T5-used strategy and did not answer; T6-did not answer.

The proposed problems were: Problem 1: Junior will make a $280 \mathrm{~km}$ trip. His car consumes 1 liter of fuel every eight kilometers. How many liters of fuel he will spend? Problem 2: An industry produced 183 pieces and wants placing them in 9 boxes, so that all the boxes have the same number of pieces. How many pieces will be placed in each box? Problem 3: A marketer has a total of 960 oranges. How many packages with 15 oranges he can form? Problem 4: An elevator can carry 25 people per trip at least how many trips it is necessary to carry 1001 people? Problem 5: A cargo company charges R\$ 513.00 per tonne transported. What was the price of a cargo whose transported cost R $\$ 9.234 .00$ ?

It is noteworthy that the students' responses, both for operations with numbers as to the problems were only inserted into the table with the categories, without an analysis of the nature of the error and without an empirical data that could provide to the reader more explicit information about errors, strategies and procedures used. This information would allow inferences about students' difficulties in dividing operations with natural numbers.

The lack of such information only allows us to infer that the students present difficulties of various kinds in carrying out operations and problems involving division with natural numbers. For this reason we developed the research, whose results presented in the article, progress towards identifying the nature of some errors in division operations with natural numbers.

The article entitled “Go one”? "Lend one”? “What does that mean exactly?” by Prieto (2016), points out that the addition and subtraction operations with natural numbers is a source of many problems for students when these operations require reservation. The author argues that these operations are taught as techniques to be followed as to the teaching of the algorithm to be confused with the operation.

The author argues that, for students, contact with different ways to calculate is important, and the freedom to use strategies. As an example the author presents the resolution of an addition by a student who had not yet learned about the transportation of dozen:

$$
\begin{array}{r}
15 \\
+17 \\
\hline 212
\end{array}
$$

\begin{tabular}{|lll|}
\hline Cálculo mental & $\begin{array}{l}\text { Procedimento 1 } \\
\text { (a subtração não é apresentada }\end{array}$ & $\begin{array}{l}\text { Procedimento 2 } \\
\text { (a subtração é apresentada) }\end{array}$ \\
$280 \div 8=35$ & $280 \quad \frac{8}{35}$ & $280 \frac{8}{35}$ \\
& $\frac{40}{0} \frac{-24}{040}$ \\
& $\frac{-40}{00}$ \\
\hline
\end{tabular}

Source: A study about division of natural numbers with students from 5th grade elementary school by Oliveira (2016).

Figure 4. Resolution procedures in the division operation with natural numbers. 
The author says that the perception of error by the student can be performed if a specific job with the decomposition of numbers is performed. In this case the student may see that by decomposing 15 and 17 in $10+5$ and $10+7$, respectively, would obtain a sum close to 30 , since $10+10=20$ and $5+7=12$.

The same could be done for $29+32$, rounding 29 and 32 to 30 and 30, respectively, placing the result around 60 . Or performing decompositions: 32 as $30+2$ and 29 as $20+9$. Adding 2 with 9 more one decomposition in $10+1$.

According to the author: "If we want our students have contact with the algorithm, but that does not learn it as a series of meaningless steps and also try other strategies, it is important to give them time to research, exchange experiences with their classmates and "invent" ways to calculate, before learning algorithm” (p. 5, our translation).

The subtraction operation will also put its challenges, according to the author, when the need for loans. In this case the decomposition should also precede the teaching algorithm so that loans can acquire meaning. Example presented by the author (Figure 5) to perform the subtraction 72 - 38.

By using the algorithm, both lends procedure as the slide 1 procedure (Figure 6) acquire meaning.

By cutting the 7, so that it "lends 1" to 2, the following steps are performed:

1) We separate one of tens of 70, turning it into sixth dozen + 10 units;

2) We join the 10 units at 2, totaling 12.

It is very important to remember that this armed account, the 7 is not only 7 , in fact, it still holds 70 , or 7 dozen. When "lends 1", it is lending a ten, which joined the two units, turning 2 in $12(10+2)$.

It is more or less what the student did, to turn 10, those that decomposed the 72, in ten sticks. He did not join these ten units to the other two because, in his calculation, this would not be necessary. But in the algorithm it is.

According to the author in the "slide" account also lends one, but this one "slide" is added to the subtrahend, whose explanation for this case also relies on the decomposition (Figure 7).

Therefore, adding 10 to the two terms, the subtraction result remains the same. Teaching students that, in 72 , 7 worths 70 or 7 groups of 10; one of these groups of 10 represents 10 units, and so on, it becomes easier to understand.

It is noteworthy that in this article the author refers to the difficulties to perform additions and subtractions with reservation meanwhile proposing a possible way of overcoming this difficulty.

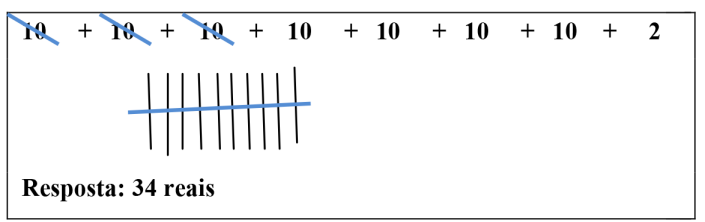

Source: Article entitled: “Go one?” “Lend one”? “What does this mean exactly?” by Prieto (2016).

Figure 5. Subtraction operation performed by a student.

\begin{tabular}{|rr}
72 & 672 \\
-38 & -38 \\
\hline & $\frac{-34}{34}$
\end{tabular}

Source: Article entitled: “Go one?” "Lend one”? "What does this mean exactly?” by Prieto (2016).

Figure 6. Procedure "slide 1" to perform the subtraction operation.

\begin{tabular}{|l|l|}
\hline $7^{1} 2$ & $\begin{array}{l}\text { Este pequeno } 1 \text { junto às unidades significa que acrescentamos } 10 \text { ao } 72 \text { ficou } \\
70+12\end{array}$ \\
\hline${ }^{4} \mathbf{3 8}$ & $\begin{array}{l}\text { Este pequeno } 4 \text { junto às dezenas significa que acrescentamos } 10 \text { também ao } \\
30 . \text { Em vez de } 3 \text { dezenas ficam } 4 \text { dezenas. Agora temos } 48 .\end{array}$ \\
\hline
\end{tabular}

Source: Article entitled: “A Go”? "Lend a”? "What does this mean exactly?” by Prieto (2016).

Figure 7. Procedure Explanation of the "slide 1" to perform the subtraction operation. 
With the presentation of these studies and reports we observed that in fact the operations with natural numbers is a source of difficulties for students. The identification of the nature of these errors is fundamental to the organization of activities that can both contribute to the students' difficulty, as to prevent them from arising.

\section{Methodological Procedures}

The investigation was forwarded in a qualitative approach with reference an instrument of empirical data collection, with ten questions, with four types of mathematical operations: addition, subtraction, multiplication and division to four groups of the 6th grade of a public school with about 30 students in each group. The application was made by a teacher in the four groups of 6th year in which she taught. Totaled 120 (one hundred twenty) students, 30 from each one of the four (4) classes of the sixth grade. All responses submitted by 120 students, the ten questions proposed, characterized the empirical data that were submitted to analysis in the light of Conceptual Fields of Gérard Vergnaud. The ages of the students ranged from eleven (11) to twelve (12) years. There were 78 (seventy eight) girls and 42 (forty-two) boys who answered the proposed questions. It is noteworthy that not investigated in this study, the interference of gender in the identified errors, because this was not the intention of the study. However, by means of the available empirical data, this correlation can be fetched in a later study.

As the empirical data referred to the answers of all students in four classes, we consider reliable sample, because there is no interference, neither the researchers nor the teacher of the class. All students were of the same public state school, in the city of Ponta Grossa, Paraná, in Brazil. In fact the analysis of empirical data arose because of the request of the teacher, who needed to know the nature of the various and different presented errors. Therefore these data have not suffered the intervention of researchers.

Her intention was to check the students' performance in the resolution of these operations. Surprised by the results, he came to our group of studies and research ${ }^{1}$ to understand the children's difficulties, the nature of the presented errors and make pedagogical decisions about the learning operations. Front this situation we base our analysis on the activities proposed by the teacher. Questions can be seen in Table 1.

The answers presented, by written, were analyzed in the light of the Theory of Conceptual Fields, in relation to the type of the identified error.

\section{Analysis of Students' Productions}

To analyze the mathematical production of the students, we used the theory of conceptual fields of Gérard

$$
\text { Table 1. Questions proposed to the student's. }
$$

Question A: Addition without recourse to the top order, with two portions of two numbers: $35+$ 42.

Question B: Addition with recourse to the top order, with two portions, being the first with three numbers and the second with four numbers: $278+3456$.

Question C: Subtraction with recourse to the top order in the order of tens with three numbers in the minuend and in the subtrahend: $839-454$.

Question D: Subtraction with recourse to the order of the tens and of the units, with three numbers in the minuend and in the subtrahend: $942-583$.

Question E: Multiplication by 1 with three numbers in the multiplier: $121 \times 1$.

Question F: Multiplication by zero and with three numbers in the multiplier: $784 \times 0$.

Question G: Multiplication of one number in the multiplier by three numbers in the multiplicand: $743 \times 2$.

Question H: Multiplication of two numbers in the multiplier and in the multiplicand: $45 \times 16$.

Question I: Division of 100 by 2.

Question J: Division of a number with three digits in the dividend by one digit in the divider.

${ }^{1}$ The GEPAM (Group Studies and Research Learning Math) institutionalized in State University of Ponta Grossa, is dedicated, among other activities, the research on theoritical basic in the theory of Conceptual Fields of Gérard Vergnaud. 
Vergnaud for enabling the analysis of mathematical issues resolution procedures, explaining the understood meanings in the ways of thinking used by students and subsidized by a theory of knowledge in the epistemological and psychological dimension. This reference of analysis enabled to point out the ways of the students' thinking, when made explicit, or infer about them when not explicit. We also support in Fayol.

According to Vergnaud (1990: p. 155), the theory of conceptual fields works with the idea of the situation and the action of the subjects in these situations. The author recognizes the importance of Piaget's theory for the theory of conceptual fields and highlights two Piaget's concepts: the concept of schema (invariant organization of behavior for a given class of situations) and operative invariant.

The errors were analyzed in relation to the schemes, according to the author, let investigate the knowledgein-action of the subject, specifically in relation to the categories of elements: goals and anticipations, action rules, operative invariants (concepts and theorems on act) and possibilities of inference in situation.

To explain the different types of errors presented, the assumptions made, the concepts not built and the meanings attributed to different solutions, we present the analysis of resolution procedures, in "Figure 8".

The errors were grouped according to the nature or common feature. Through the analysis faced with addition or subtraction errors in both addition and subtraction as well in the multiplication operations and also multiplication tables errors. The following empirical data illustrate these errors.

Adding errors, both operations of addition and multiplication mobilized the theorem Card A + Card B = Card $(A+B)$. Whatever the strategy used—count all or count following — will mean that the student is making use of a theorem in action. While concepts are needed numerals that undergo addition of situation mobilize theorems in action (the count units or groups and, in this case, it is necessary to follow the counting logic: count all, count only once and repeat the numbers in the same order) and the cardinality (establish relations of order and hierarchical inclusion). These theorems students must dominate to operate properly.

The errors shown in subtraction allowed the identification of concepts and theorems in act necessary for the proper conduct of subtraction operation.

To the problems of subtractions, Fayol (1996) has different types of procedures, "separate from" that is to form the largest set and remove that the smaller set and count what remains and can also be used by counting without object that is to "count backwards from", the largest of the terms, decreasing one by one until withdrawn the lowest terms; "separated until" which consists of removing the larger set objects to let subsist only the number that corresponds to the smaller of the two terms provided and can be used by counting without an object consisting of "count back up" from the greatest of terms to achieve the lowest, enumerating the elements of the obtained sequence; addition from the least of the amounts go to higher increasing one by one, and the number of added elements provide the response (complement of the procedure); direct recovery in long-term memory of numerical facts $(6-4=2$ or $17-8=(16-8)+1=9)$.

For students analyzed we can infer from their written productions that strategies "count backwards from" or "count back up", related to the difference in procedure or count up, related to complement the procedure, fail leading children present subtraction errors. These strategies require counting concepts and also the manipulation of objects, fingers or mobilization in thought in the correct order of the number sequence recited in reverse order. Similarly to the addition theorem mobilize Car (A) - Car (B) = Car (A - B).

It is attributed to errors by misunderstanding the SND structure, the lack of meaning to written numerals, and also the operations of addition, subtraction, multiplication and division. The productions related to these types of errors pointed out different procedures as explained in sequence, followed by empirical data.

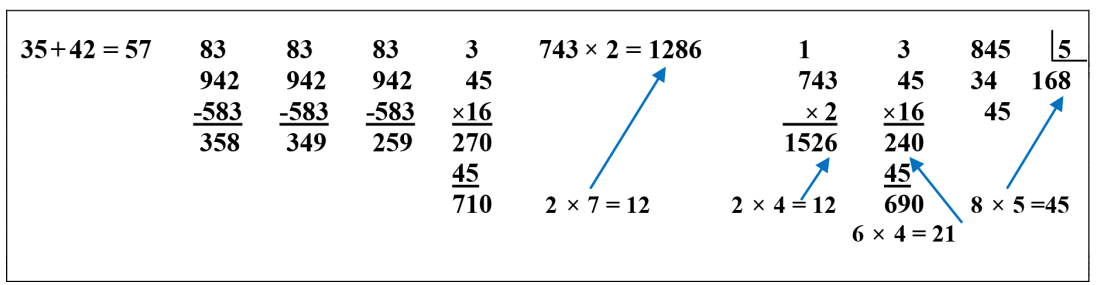

Source: the authors.

Figure 8. Some resolution procedures in the operations of addition, subtraction, multiplication and division with natural numbers presented by some participating students. 


\subsection{Mistake in Misunderstanding SND}

- Positioning units beneath dozen or not align the digits in the algorithm as relative value (by performing a multiplication treats each multiplier digit as an absolute value (units) and not relative and, therefore, misses the result of the position to add adding a zero to the right of the numeral, without the perception of change in the relative value of the digits of the arabic notation) to align the numerals in the algorithm. The theorem in action took this student to "level for the left" may be related to a use of memory fragment division algorithm or the fact that the lower portion have been up.

$$
\begin{array}{rc}
2780 & 278 \\
+3456 & +3456 \\
\hline 6236 & \frac{6236}{6}
\end{array}
$$

- Assign relative value to the loan amount, resort to loan incorrectly (lending units to the tens, the tens to the hundreds, ...), consider the loan as a unit by adding to the number of units like if it was an unit, and in the dozen spot as it was not possible to remove subtracted the lower 3 of the most 8 .

3

$942+1$

$\frac{-583}{450}$

\subsection{Meaningless in Digits of Numeral}

- Treating each digit as a single unit and, therefore, the subtraction is performed with these isolates numerals as in the numeric field of natural, this operation is only possible by removing the smallest from the highest. Subtract the smaller number of the bigger one, alternatively, whether the number is the minuend or subtrahend.

$$
\begin{array}{rr}
942 & 454 \\
-583 & -839 \\
441 & 425
\end{array}
$$

- Consider the numbers as isolated units and not assign significance to the subtraction operation and for this reason, either subtract and add these numbers, (when the withdrawal is not possible because the subtrahend is bigger than the minuend).

1

$$
\begin{array}{rr}
839 & 942 \\
-454 & -538 \\
\hline 485 & 525
\end{array}
$$

The theorem in action that mobilizes these forms of common error appears in several studies (Zunino, 1995; Parra, 1996). They always turn to take the lowest of the biggest no matter the order of the portions in operation.

\subsection{Errors in Addition Operations, Subtraction, Multiplication and Division}

- Forgetting to register the loan.

$$
\frac{-454}{485}
$$

Treating each multiplier digit in function of its absolute value (units) and not relative and, therefore, error of the position result to add (in this case does not understand what is multiplied by 10 when operating in the dozen 
digit in multiplier), besides making other errors (of multiplication tables and not to add the reservation).In this case three different solutions are presented and in all of them students show little skill in the field of multiplication algorithm: 1) The first from left to right: the student forgets to add the reservation and aligns the addition at the bottom as if was dozen; 2) The second aligns as the previous one; 3) The third does not know the multiplication table, aligns wrong and adds even relying on a reservation that does not exist.

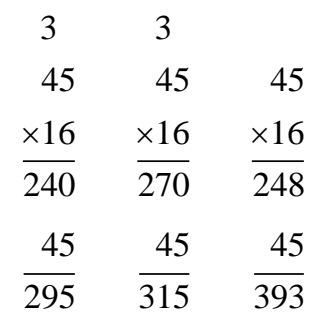

What theorem in action is common to these three mistakes? It seems to be winning that when they learn to build the counts the teacher says "units below units and dozens of dozens etc". But in the multiplication with a multiplier with dozens, or the second portion is ten or hundred or thousand etc. depending on the multiplicand. This changes the configuration of the operation, but not the theorem in action.

\subsection{Error for Not Knowing How to Deal with Zeros of a Numeral (Interleaved or Not)}

- $\quad$ Place 5 in response, not 50.

$$
\begin{array}{ll}
100 & 2 \\
0 & 5
\end{array}
$$

When the student operates not think "how much divided by how much", but "do the math”. Failure to put the zero in the quotient stems not make sense to divide zero by two and he does not know how to register.

Think of zero as representing nothing was common in the analyzed operations. The fact is that zero is the basis of two, or three, important advances in mathematics. First in the creation of positional system of the Babylonians to write numbers, based on the grouping of 60 . Since the system is positional zero appeared to mark the absence of powers in a certain position.

Zero began its life as an occupant of place and the Hindus used a small circle as an occupant of place symbol and also gave a conceptual leap to recognize the Sunya (the absence of quantity) as an amount in its own right. They had begun to recognize the zero as a number.

The mathematician Mahāvīra (c. 850) wrote that a number multiplied by zero results in zero, and the zero subtracted from any number does not change the number.

The most important of these occurrences is not which of India's mathematicians had the right answers when calculating with zero, but the fact they put these questions first. To calculate with the zero we must first recognize it as "something", an abstraction like any other number, that is, one must go to count a goat, or two cows, or three sheeps, or think of 1, 2, 3 themselves, as things that can be manipulated without thinking about the nature of the objects being counted. We have to think of $1,2,3, \ldots$ as quantitative ideas, even if they are not counting anything. Then, and only then it makes sense to treat the zero as a number.

As the mathematical record was spreading and people learned to calculate the new numbers, it became necessary to explain how to add and multiply when one of the digits was zero. This helped to resemble a number.

However, the idea of the Hindus that they should treat zero as a proper status number took a long time to settle in Europe. Even some of the most prominent mathematicians of the sixteenth and seventeenth centuries would not accept zero as root (solution) equations.

These historical issues need to be redeemed if we want to understand the children's difficulties in assigning meaning to zero which is revealed to take it as written record.

\subsection{Error for Reversal of Manupulation Algorithm, for Reversal of Minuend and Subtrahend Terms and for Reversal of the Operations}

- Do not assign significance to the quotients obtained by dividing 


\section{$845 \underline{5}$ \\ $-4598$ \\ $\overline{800}$}

Here the theorem in action is "how many times five fits into 845" only obeying the order of addition and subtraction algorithms starts on the right (45 for 5 result 9).

Spatially reproducing the algorithm of additive structures as previously identified by Muniz \& Bittar (2009), and manipulate the algorithm as the addition, i.e. starting from the right (zero divided by 2 gives zero and 10 divided by 2 gives 5).

$$
\begin{array}{r}
100 \\
\div 2 \\
\hline 05
\end{array}
$$

- Check that in the spot of the units was not possible to subtract 3 from 2, did the opposite and placed as a result the number $1(2-3=1)$ and the dozens made use of the resource usually.

$$
8
$$$$
\not 42
$$$$
\frac{-583}{361}
$$

Another hypothesis is that when checking is not possible to take off 2 of 3 and 4 of 8 , started lending from nine which was bigger than five (such laying 8 upon nine, because lent 1) and takes off 3 . There are 14 in dozen spot. Took off 14 of 8 and left 6 . As it was used "all" (the reservation $10+4$ ) could not lend to the two and takes off 2 of 3 lefting 1.

Divide rather than multiply or multiply instead of divide.

Reversed operations, but operated properly.

$$
\begin{array}{lrr}
45 & 16 & 100 \\
13 & 2 \\
& \times 2 \\
& & 200
\end{array}
$$

- To add instead of multiplying only one of the numbers in the multiplier

$$
\frac{\times 16}{111}
$$

\subsection{Error for Performing Adding and Subtraction Operations in the Same Algorithm}

- Add and multiply in the same operation by adding the unit, multiplying the dozen and adding the hundred (does $2+3=5,2 \times 4=8$ and $2+7=9$ ).

$$
\begin{array}{r}
743 \\
\times 2 \\
\hline 985
\end{array}
$$

One of the hypothesis for this case seems to be that when you forget the multiplication tables, addition or multiplication sign was confused with the addition one.

\subsection{Error for Interpret the Digit of the Numbers as Units and Not Completing the Multiplication Operation}

- Multiplying the unit of the multiplyer by the multiplying unit, registering the reservation that is added to the 
dozen 3 and the summation multiplied by 1 (taken as a unit).

This procedure in situation reveals partial knowledge or ignorance of algorithmic procedures.

- Only multiply the units multiplier for multiplying $(6 \times 5=30$, leads the reservation and add to the product of $6 \times 4)$ or by multiplying the house of the multiplier of tens (considered a unit) of digits of multiplying $(1 \times$ 5:01 $\times 4)$.

$$
\begin{array}{lr}
3 & \\
45 & 45 \\
\times 16 & \times 16 \\
\hline 270 &
\end{array}
$$

\subsection{Error in Subtracting Tens from Units}

- Subtract instead of add (in this case has to admit the possibility of substitution have occurred because of the reservation (can not remove a bigger value of a lower value). For example: to the resolution of $35+42$ student who made a subtraction result being 272. The register of the solution enabled us to identify the following: when using the algorithm had to borrow to be able to subtract 4 tens of 3 tens. Did this borrowing from the units (there were 5 units, left 4 units). However, the loan of a unit was placed next to the number 3 of the tens, i.e. juxtaposed (and not added, being 31 to remove tens 4 dozen).

$$
\begin{array}{ll} 
& 4 \\
31 & \not 5 \\
4 \quad 2 \\
\hline 27 & 2
\end{array}
$$

The errors in the meanings attributed to loans, positioning of the numerals in the algorithm or no possibility of withdrawals, were analyzed in relation to the goals set by the child who understood rules based on concepts in act related to SND structure.

The child performs a subtraction operation and creates chances from the meaning given to this written numerals. This meaning does not understand the knowledge of the structure that is present in this type of record (base ten positional). For this reason, she performs the operation 35 - 42 and, by failing to remove 4 (tens) of 3 (tens), lends 1 of 5 (which is unit) and puts this numerical value to the right of the 3 tens interpreting the new value as 31, removing the 4 tens (considered 4 units), obtaining 27.

\subsection{Error in Subtract Always the Smallest from the Biggest Regardless if the Digit Is from Minuend or Subtrahend}

The same analysis allows interpret the procedures which children subtract the smaller of the higher, no matter if the register number is the minuend or subtrahend $(3-2=1,8-4=4$ e $9-5=4)$.

$$
\begin{array}{r}
942 \\
-583 \\
\hline 441
\end{array}
$$

In this case the child works with the numbers of the numerals as if they were juxtaposed numbers because not assign significance to the number of representation registration. Prepayments comprise rules of action that explain concepts in act used (the subtraction situation, in this case, which mobilizes the theorem in action: remove the smaller of the higher) and schemes that obtaining results (using the algorithm that mobilizes theorems in action weakened that hinder the understanding of SND structure). 


\subsection{Error in Zero Addition to the Right of the Numeral}

Such inferences can also justify the case which the child completes with a zero to the right in a numeral with less digits to add another with more digits. The no significance to the number of registers of representation underlies the child's actions that support the algorithm procedure, mechanized, but that gives you confidence to believe that you will get the result. This procedure is performed according to instructions received, i.e. putting the numbers one below the other and, in this case, zero is added to have no value and "fill an empty spot".

$$
\begin{gathered}
278 \\
+3456 \\
\hline 6236
\end{gathered} \Rightarrow \begin{array}{r}
2780 \\
+3456 \\
\hline 6236
\end{array}
$$

\subsection{Errors Associated with Meaning Allocation Lack to Multiplication by 1 or by Zero}

- To add a unit to each digit, $121 \times 1=132$ or double the numerical value multiplied by $1,121 \times 1=242$. The hypothesis is based on the increase, arising from the theorem of the idea in action of successive additions: multiply always increases and for this reason either doubles and either adds a unit.

- Multiply by zero gives the same number $784 \times 0=784$ (theorem in action: "zero plus something does not change anything" does not work for multiplication) or by adding a zero to the right of multiplying $784 \times 0=$ 7840 (theorem in action, "any number times 10, adds a zero to the end", but the multiplier is 0 and not 10).

Zero is treated as neutral element in this operation or as representing a multiplication by ten.

The results of multiplication by 1 and by zero could be achieved without the use of the algorithm if the child was in possession of the concept of multiplying. The same applies to the multiplication by two that could be performed without the recurrence to algorithm if coupled to the conceptualization of SND structure. The various occurrences in these cases highlighted the difficulty in understanding the mathematical writing.

The correct application of the algorithm, but with additions of the multiplicand to multiplier digits $(121 \times 1=$ $232)$, or the duplication of these numbers $(121 \times 1=242)$, or the invariance of these numbers in the multiplication by zero $(121 \times 0=121)$, was analyzed in relation to the scheme and as a consequence, the anticipations and action rules whose theorems in act reveal a mistaken attribution of meaning in relation to the operation representation of register in the form of written algorithm. In another context can be that the child assign a different meaning to take her to present the correct result of the operation.

In our daily life do not manifest situations which we need to multiply by 1 or dividing zero by 2. Prevails in this case the idea is to increase to multiply (idea successive addition) and this idea has to be associated with the written record that manifests the signal $\times$ (times). Or prevailing the idea that zero does not change anything (transported from the addition) and, for that reason, to see the signal $\times$ (times) the written register that carries significance to the result.

The child's anticipation, for the use of the algorithm is based on an action rule (schema) that reveals to resort to an act in theorem on the SND structure that is based on own assumptions (which do not respect the positional value) in relation to the numerical writing numerals leading her to place the numerals in mismatched relative positions. In this fact is associated with the use of a theorem in fragile act (related to the addition) that does not allow the child to realize the resulting cardinality of this addition revealed by the obtained summation.

\subsection{Error As a Result of the Space Reproduction of Algorithm Structures Additive for Holding the Multiplication or Division}

As previously identified by (Muniz \& Bittar, 2009), this procedure takes the child to manipulate the division algorithm, that is, starts from the right (zero divided by two results zero and ten divided by 2 results 5) or does the multiplication of the unit making a reservation and then makes dozen times dozen, interpreting as really ten (1 dozen times 7 tens results in 7 dozens).

$$
\begin{array}{ccc}
3 & & \\
45 & \text { ou } & 100 \\
\times 16 & & \div 2 \\
\hline 70 & & 05
\end{array}
$$


In these two cases applies the addition algorithm for performing multiplication (add unit with unit and ten to ten). This error has to be interpreted in relation to the situation. The situation of adding or subtracting unit/ten with (of) unit/ten remains invariant for the child to perform the multiplication operation. Performing the operation to get the result, the child anticipates that must multiply unit/ten per unit/ten that characterized the rules (theorems) which commanded the action. These rules, in turn have to be attached to the situation concepts and theorems in act (operative invariants) that in this case, for a new situation, the multiplication, are weakened. In this case is the theorem in action used in multiplication and gives the possibility of certain inferences specifically do the same as in addition.

These procedures reveal an anticipation supported on assumptions built by the child in relation to the meaning attributed to the multiplication algorithm. In this case the scheme still relies on a mistaken concept, and, therefore, hypotheses that can be refuted intervention procedures by means of cognoscitive challenges. These assumptions are built because of not attributing significance to the algorithm procedure. The child knows that each digit of multiplicand relates to each digit of the multiplier. As this concept is wrong, she/he instead of multiplying, adds, and forgets of the dozens digit.

\section{Final Considerations}

By identifying some of the students' difficulties of the 6th grade of elementary school, to carry out the operations of addition, subtraction, multiplication and division with natural numbers, the nature of the recurrent errors by students resulted from the understanding of the structure of the decimal, the structure of the algorithm or the organization of representation registers (numeric and written word).

The analysis allowed the explicit understanding of SND by students, at the time of use of operative algorithms and unveiled the chances that they manifested to justify strategies and procedures used to perform these operations. When proceeding with analysis subsidized by the theory of Conceptual Fields was possible to point out the conceptual field (set of situations and set of concepts) necessary to carry out these operations.

From the evaluation of the errors made it possible to the teacher reorganize her pedagogical practice with forms of intervention for these errors were overcome. A study of the subsequent performance work by the teacher was not performed. Also the activities organized by it to overcome the difficulties.

By manipulating the algorithms students made use of the same schemes (starting from right to left for additions, subtractions and multiplications and from left to right in the case of divisions), however the errors were caused by the non identification of the SND structure in the written notation. Therefore they borrow by subtracting one unit of tens (or vice versa) and they added to units or juxtaposed to them, or worked with the absolute value of numeral digits.

We will have to investigate whether the mistakes made by our children are due to the misunderstanding of SND structure, or misunderstanding of the algorithm or if the schemes would generate own creations that would work if there was understanding of the SND.

Importantly, in the interventions will consider the students' productions and show the used schemes and assignments of meaning to the digits of numerical notation that lead to different solutions. This should be done taking advantage of the arguments used while socializing with other classmates. These are productions that can support intervention proposals for overcoming obstacles (epistemological or pedagogical) and conceptual advances.

Also, and not least important, the organization of a work aimed at understanding the SND structure (Brandt, 2005) present in representation of data used to represent numbers and the form of organization of the different registers: word (suffixes and prefixes) and written notation (absolute value and relative value of digits). Thinking about skills to the development of strategies related to mental calculation and memorization of small sums.

The scheme is a product of psychological order supported in the mental representation. The written productions are not able to provide the broad and complex children's constructions. It is therefore necessary to supplement the register with justifications and arguments that reveal what is not made explicit.

Such intentionality implies considering the diversity of human thought in the organization of educational practice and, therefore, carries a didactic transposition of the produced scientific knowledge, not taking as ready and finished, contemplating interests, necessities, difficulties, first intuitions, possibilities, approaches, referrals, strategies, among other issues.

Also consider the need for a differentiated teacher's look in relation to children's productions seeking to un- 
derstand them, accept them when correct, even though different or non-canonical, socialize them to value the epistemic subject who is able to think and to produce knowledge, understanding them as fragile or arising from development processes, and contribute to the breaks required by cognoscitive challenges and problems found.

This different way of looking entails personal disruptions arising from our training processes, both as a professional and school, in teacher training courses. These disruptions will mean deconstructions and reconstructions of conceptual, procedural and professional nature, as pointed out by Muniz \& Bittar (2009).

From the found results you can make inferences and answer the questions posed by the research. There are several concepts and theorems put into action to carry out the operations of addition, subtraction, multiplication and division with natural numbers. The concepts and theorems in action related to the misunderstanding of the decimal numbering system structure are responsible for the errors. The errors are due also misunderstanding of the algorithms structure and how to manipulate them. The mistakes are due to the understanding of the organization of representation of records, in the studied case the SND structure in Arabic notation.

The presented results indicate to proposed activities aimed at overcoming the difficulties (games) and the understanding of the SND structure (Lisboa reasoned Arithmética, by Zuin (2005) and conducting decomposition before manipulation of algorithms and for understanding the same as proposed by Prieto (2016)) to name a few.

These proposals must aim to understanding the SND structure to only after, enter the algorithms for operations with natural numbers, noting that there should also be learning these algorithms.

\section{References}

Bertini, L. de F., \& Passos, C. L. B. (2016). Learning Difficulties Arithmetic in the Early Grades. http://alb.com.br/arquivomorto/edicoes anteriores/anais16/sem15dpf/sm15ss08 02.pdf

Brandt, C. F. (2005). Contributions of Representation Semiotics Records in Concepts Numbering System. Florianópolis: Federal University of Santa Catarina.

Fayol, M. (1996). The Child and the Number: From the Account to the Problems’ Resolution. Porto Alegre: Artes Médicas.

Felício, C. M. P., \& Policarpo, F. (2015). The Use of Games as a Teaching Resource. In P. Grossa, \& P. Anais (Eds.), XIII EPREM: Practice and Research in Mathematics Education (pp. 1-9). Ponta Grossa: UEPG.

Muniz, C. A. B., \& Bittar, M. (2009). The Mathematics Learning from the Perspective of Conceptual Fields Theory. Curitiba: Editora CRV.

Oliveira, A. R. L. (2016). A Study about Division of Natural Numbers with Students from 5th Grade of Elementary School. http://int.search.myway.com/search/GGmain.jhtml?searchfor=UM+ESTUDO+SOBRE+DIVIS\%C3\%83O+DE+N\%C3\% 9AMEROS+NATURAIS+COM+ALUNOS+DA+5\%C2\%AA+S\%C3\%89RIE+DO+ENSINO+FUNDAMENTAL\&cb=B YM\&n=782a0cc8\&p2=\%5EBYM\%5Exdm019\%5ETTAB02\%5Ebr\&ptb=1914DD24-F06F-42D7-B71F-D2F386D334D8 \&qid=8bc3320ea1f84020975ff43a83bbe92c\&qs=\&si=\&ss=sub\&st=tab\&trs=wtt\&tpr=sbt\&ts=1468154200081

Parra, C. (1996). Mathematics Didactics-Psychopedagogical Reflections. Porto Alegre: Artmed.

Prieto, A. C. S. (2016). Go One? Lend One? What Does That Mean Exactly? http://www.planetaeducacao.com.br/portal/artigo.asp?artigo $=590$

Vergnaud, G. (1990). La théorie des champs conceptuels. Recherches em Didactique de Mathématiques, 10, $133-170$.

Zuin, E. de S. L. (2005). The Four Fundamental Operations in “Arithmética Reasoned” by Pedro D’Alcântara Lisboa, Published in 1983. Magazine Education Issues, 23, 31-52.

Zunino, D. L. (1995). Mathematics at School: Now and Here. Porto Alegre: Artes Médicas. 


\section{Submit or recommend next manuscript to SCIRP and we will provide best service for you:}

Accepting pre-submission inquiries through Email, Facebook, LinkedIn, Twitter, etc.

A wide selection of journals (inclusive of 9 subjects, more than 200 journals)

Providing 24-hour high-quality service

User-friendly online submission system

Fair and swift peer-review system

Efficient typesetting and proofreading procedure

Display of the result of downloads and visits, as well as the number of cited articles

Maximum dissemination of your research work

Submit your manuscript at: http://papersubmission.scirp.org/ 